\title{
CURRICULUM ENHANCEMENT AND EVALUATION OF GRADUATE ATTRIBUTES AND OUTCOMES THROUGH STUDENT-RUN FORUMS
}

\author{
Dario Schor, Kathryn Marcynuk, Matthew Sebastian, Witold Kinsner, Ken Ferens, Cyrus Shafai, and Nariman Sepehri* \\ Department of Electrical and Computer Engineering \\ *Faculty of Engineering \\ University of Manitoba, Winnipeg, MB, Canada, R3T 5V6 \\ \{dschor|umsebasm|kinsner|ferens|cshafai\}@ece.umanitoba.ca, \{ummarcyk|nariman\}@cc.umanitoba.ca
}

\begin{abstract}
The evolution of a curriculum involves changes at many different levels such as daily changes to reflect questions or areas of interest of a particular class, improvements to an established course based on observations from the professor, or more significant changes to streams of courses at a departmental level, or adaptation to suggested accreditation guidelines such the recent new Canadian Engineering Accreditation Board (CEAB) graduate attributes and outcomes. Most educational institutions have means of collecting data and assessing individual courses or streams of courses based on student performance, course evaluations, and professor assessments. However, since more can be done to gauge the collective effect of changes before students get to their final year capstone project or go into industry, a student-run curriculum forum has been established.

This paper presents some of the lessons learned from the bi-annual student-run curriculum forums in the Department of Electrical and Computer Engineering at the University of Manitoba. Based on the experience acquired so far, this paper outlines the organization of the curriculum forums, suggestions on guided discussions, ways to present feedback, and means of communicating to students how their feedback is being used to improve the curriculum.
\end{abstract}

Keywords: Graduate attributes and outcomes, cooperative curriculum development

\section{INTRODUCTION}

The evolution of a curriculum involves changes at many different levels such as daily changes to reflect questions or areas of interest of a particular class, improvements to an established course based on observations from the professor, or more significant changes to streams of courses at a departmental level, or adaptation to suggested accreditation guidelines such the recent new Canadian Engineering Accreditation Board (CEAB) graduate attributes and outcomes. In small, upper year electives where instructors have much interaction with students, it is easy to gauge the effect of the changes and make adjustments during the course. For large core courses primarily in first and second year, the impact on any changes made to the curriculum is not obvious until long after the course is over when the student needs to recall the fundamentals to solve a problem in a subsequent course. Most educational institutions have means of collecting data and assessing individual courses or streams of courses based on student performance, course evaluations, and professor assessments. However, since more can be done to gauge the collective effect of changes before students get to their final year capstone project or go into industry, a student-run curriculum forum has been established.

Another major reason for holding the student curriculum forums is the need to educate the students about the new CEAB graduate attributes and outcomes [Kins10]. Repeated discussions have been required to achieve a satisfactory level of understating what the attributes entail, and how they can be attained in various undergraduate courses. This grass-roots input appears to be essential in achieving the objectives of the intended CEAB attributes and outcomes. In order to complete this process, we have also proposed and implemented industrial curriculum forums through the Education, Management and Professional Communication (EduManCom) Chapter of the IEEE Winnipeg Section[FeKi11].

This paper presents some of the lessons learned from the bi-annual student-run curriculum forums in the Department of Electrical and Computer Engineering at the University of Manitoba. The forums are facilitated by undergraduate and graduate students that sit on the department's Computer Engineering Curriculum Committee that guide discussions on (i) specific changes implemented to the curriculum, (ii) feedback on courses and instructors, (iii) student group activities, and (iv) outreach. The anonymous feedback is presented to the curriculum committee where the appropriate actions are taken to address the concerns. Students will also be included in other programs. Based on the experience acquired so far, this paper outlines the organization of the curriculum forums, suggestions on guided discussions, ways to present feedback, and means of communicating to students how their feedback is being used to improve the curriculum. 


\section{SPECTRUM OF CURRICULUM FEEDBACK}

There are many stakeholders that dictate the curriculum for a university program, most of whom are academics, educators, and practicing engineers. These individuals shape the program based on input from different sources such as personal discussions with students, course evaluation forms, departmental committees, and the accreditation board. The following sections describe some of the common sources of curriculum feedback.

\subsection{Informal Course Feedback}

Informal individual course feedback comes from discussions between professors and individual students before or after class. The discussions focus on course content and delivery, and they serve as a measure of student engagement in the course. This type of feedback fosters the student-professor relationship. For the student, this is a venue for immediate feedback, while professors use this to adjust day-to-day lectures in order to better suit the learning needs of the students in the course. This is generally easier for professors that have taught the course multiple times and thus feel comfortable adjusting the delivery and examples for the current group as long as the material emphasized does not differ from other sessions of the course being offered at the same time. As students become more comfortable speaking to the professors, the quality of feedback improves, thus helping close the feedback loop for the course.

The informal feedback is limited in its scope; not all students feel comfortable talking to professors in large classes. This is even more difficult in courses with beginning students who may feel intimidated. In addition, this type of feedback relies on the interest and availability of professors. Those that leave immediately after class may not get the same amount of face-to-face interaction to make students feel welcome in a one-on-one setting during office hours.

\subsection{Formal Course Feedback}

Formal course feedback at the University of Manitoba is provided in the form of Student Evaluations of Educational Quality (SEEQ). This course evaluation is managed by the University close to the end of each course. At the University of Manitoba, these consist of 41 core multiple choice questions and additional space for open ended feedback. The evaluation covers the course content, laboratories, textbooks, assignments, and course delivery. The results from these forms are delivered to professors after the course is completed. From the student perspective, the surveys require a lot of time to fill out and they do not see tangible results from their feedback.

The evaluations are anonymous and thus encourage all students to provide honest feedback on the course. For large classes, the statistics generated from the forms can help gauge the overall student experience which can be then correlated to grades to get a more complete understanding of the course.

The main drawback with student evaluations is that they are conducted near the end of the course and the results are not made available until after the final grades are submitted to the university. This form of feedback is less timely for small changes, and not relevant to the students filling out the form in the current course offering. As the results do not influence the current students, they are less inclined to complete the form, or provide additional comments. The SEEQ results are available to the students, but are not easily accessed or discussed.

\subsection{Curriculum Committee's Evaluation}

Each program (or discipline) in an engineering department could have a curriculum committee consisting of faculty members from the program and from other departments associated with the program (i.e., Computer Science), as well as staff, and students (both undergraduate and graduate). A committee of department staff provides a strong direction for the curriculum through evaluation and organization from a faculty level. Courses are analyzed from professors perspective looking specifically at course design, course interaction, and long term adjustments to the course flow. When necessary, course instructors and professors are brought into the curriculum meetings to provide more insight into a specific course. Additionally, student feedback can be included at the curriculum committee to approach courses from another perspective.

For example, a long term review of the full curriculum was undertaken at the University of Manitoba by the Computer Engineering Curriculum Committee in an attempt to consolidate course content and coverage from 2008-09. Evaluation of each course was done using the IEEE and ACM suggested content and by asking each professor to explain what is covered by their courses. Upon tabulation, this set of data provides a strong indication of specific content that is not covered sufficiently, or overlap repeatedly over a number of courses. Courses that have been modified over a number of years can end up looking quite differently, and this review helps to narrow the scope of the course back to the intended size. Through the review of course interactions, an assessment can also be made as to what students should know after having completed certain courses.

This periodic comprehensive overview serves to identify and correct any gaps or overlap in content that may emerge as the curriculum evolves through course additions, deletions, and modifications.

The top-level nature of this type of curriculum evaluation focuses on long term adjustment to course design and interaction making it difficult to assess the impact of changes. The effectiveness of modifications can only be determined after students have propagated through the system, so it takes a long time to re-assses courses. Furthermore, unless there are student members present on the curriculum committee, the 
outcome of course changes is only evaluated from the vantage point of the faculty members. The technical staff provides feedback on lab equipment and lab content.

\subsection{Accreditation Visits}

The Canadian Engineering Accreditation Board (CEAB) visits all engineering programs on a set basis to assure that a program meets all the national and international professional standards. These reviews are used to set a national standard for engineering education by incorporating input from student, staff, and faculty [CEAB08, CEAB09, CEAB10]. The feedback is useful because it also includes a detailed assessment of course content including laboratories, tests, and design content, as well as full overview of the topic streams covered in the curriculum. In addition, CEAB emphasizes many of the non-technical skills, such as communications and environmental impact of the profession, that are essential for every engineer, and prevent over-specialization on narrow scope topics that do not stress the broad level of thinking required in the design process.

While the CEAB provides a comprehensive review of engineering programs, the accreditation visits are only conducted every few years depending on the quality of education provided. This can only provide broader perspectives that may not influence some of the day-to-day operations that have a significant effect on the quality of education. That is, even if assignments appear to foster design elements and critical thinking, a professor's explanation of the assignment, the feedback provided, and timely return to the student are of paramount importance to make a lasting impact on the student's experience. Although the information can be obtained from interviews with students as part of the review process, the reality is that some comments that students would be more comfortable sharing with other students than in a formal review process. Thus, other means of feedback are needed to complement the interviews from $\mathrm{CEAB}$ reviewers to gauge the honest student perception of the program.

\section{FUTURE OUTLOOKS ON CEAB ATTRIBUTES}

CEAB has added a graduate attributes component to the overall accreditation process that will come into effect in 2014 [CEAB08, CEAB10]. Each engineering program must demonstrate that the students possess the twelve attributes upon graduation [Stiv10]. As well, they are faced with the challenge of gauging the long-term success of the initiative, and its impact on students. This is a difficult task that has initiated lots of discussion across the country as universities try to define and map the attributes to courses and to find elements of proof to validate their statements to external reviewers [Reme10].

As an initial step towards mapping the attributes to a course, a professor may read through the list, discuss it with his colleagues, and then select those attributes that match the material and delivery of the course [Reme10, Stiv10]. So, in the simplest case, the mapping can be considered two dimensional. Is the attribute covered to some extent in the class? If so, identify some elements to validate the statement and use them for accreditation purposes. From there, one could advance to a more complex mapping where each attribute can be classified as fully covered (i.e., lots of emphasis in the course), partially covered (i.e., links to specific units), or not addressed in a course. Further expansions can break down each category even further to generate an analytical rubric to be used in assessing the program fairly while still allowing for innovative engineering education as required by [CEAB10].

Looking ahead to 2014, how does the accreditation process change when the new philosophy comes into effect? As mentioned in Sec. 2.4, the comprehensive review incorporates elements from many stakeholders, but not all stakeholders are being educated on the attributes at the same rate. Most programs are evaluating attributes at the faculty and department level, but not all professors or instructors have an understanding of the attributes. For instance, new international staff may not have the background on the subject to properly assess their course and students may not understand how these attributes relate to their education. Even worse, students may not understand the purpose of these attributes as many still believe that engineering is all about math and science and are shocked to find out the scope of courses that are required to form a Professional Engineer. Therefore, it is imperative that we prepare ourselves for the graduate attributes and develop methods of informing students and professors alike.

The University of Manitoba Faculty of Engineering has been very active developing deep understanding of the attributes, outcomes, and their mapping into courses.

The remaining of this paper deals with the student perspective on the subject and proposes student forums as a means of informing students of the attributes, using that as an aid to define their meaning, and as a means of providing the complementary input that is necessary for CEAB reviews.

\section{ENGAGING STUDENT STAKEHOLDERS}

Curriculum content and organization is primarily influenced by faculty members through their discussions at curriculum committee meetings. While these discussions may try to include student feedback through representatives from the student body, it is difficult to obtain a broad spectrum of student opinions from questionnaires and informal conversations alone. It is also important to elicit honest feedback from students with a minimal bias, which can be difficult to obtain in a setting that is not anonymous and more specifically from younger students who have yet to develop a trusting relationship with the professors.

In addition, when it comes to the $\mathrm{CEAB}$ attributes, a grassroots approach for student feedback serves as a litmus test to determine whether the perceived impact of attributes mapped by the professors is in fact noticed or acknowledged by the 
students. For example, a professor may emphasize professionalism in all his classes and demonstrate that by stating his/her expectations in the course outline, the delivery of the course material, and the expectations for assignments and lab reports. However, if students follow all these measures and do not get feedback on assignments on a timely manner or do not see the value in course materials such as slides or textbooks, then their perception of professionalism would not match that of the professor. The students see the deadlines they must adhere to for assignments and a similar expectation is placed on the professor who should also be able to manage their time in order to exemplify the professionalism expected from the students. The misuse of lack of planning to incorporate required resources into the course is also a lack of professionalism on the part of the professor.

Student feedback is not limited to individual isolated courses. In looking at streams or full programs, students provide a holistic perspective that incorporates what they have experienced over their education. For example, the demand to have graduating engineers capable of assessing and/or understanding the impact of engineering on society and the environment is something that is not build over a small number of courses, but rather developed over the entire program. Even though the quota to address a specific issue can be met in a short time, many of the attributes must be fostered over the entire program.

\section{STUDENT-RUN FORUM}

A student-run forum addresses the challenge of obtaining time-ly feedback from a broad range of students and serves as a venue to inform students of the new CEAB accreditation standards. The initiative comes from the program's curriculum committee and its student members/representatives, who act as facilitators for the forum discussions.

\subsection{Before the Forum}

To run the event, a private room is booked at a time that would be convenient for most students in the particular program, to ensure the privacy of student feedback and encourage a high turnout. Two weeks prior to the event, notices are sent out to all students by e-mail announcing the date, time, and location for the forum. The student members of the curriculum committee place posters outside classrooms and laboratories and make in-class announcements to core courses in every year of the program inviting students to attend the forum and share their feedback. Additional word-of-mouth advertising plays an essential role in attracting students, encouraging honest feedback, and communicating the importance of such events in the long-term success of the program. These informal discussions are driven by the students running the event sharing ideas and instigating conversations around the subject in student groups (i.e., IEEE or SAE student branch) and before/after class.
Furthermore, to accommodate students unable to attend and to encourage students to think and discuss ideas prior to the forum, a quick anonymous online survey is sent to all students a week prior to the event. The survey consists of four parts (i) demographics, (ii) general open-ended feedback, (iii) CEAB graduate attributes, and (iv) forum statistics. The demographics section asks for the student's program, year in program, and expected length of program (i.e., are students taking more than four years to graduate?). This serves gauge where the input is coming from and helps identify which course within a stream is causing problems for students. The only open-ended questions ask students to articulate their feedback on the program as a whole and thus broaden the scope of written feedback seen in the SEEQ evaluations. The CEAB attributes serve to introduce students to the ideas and get their interpretation and input on how the program meets the attributes. Lastly, the forum statistics are introduced as a means to measure the effectiveness of the forums. These questions ask students if they attended previous forums, if their concerns from previous forums were addressed, and if they plan to attend this forum.

The survey of CEAB graduate attribute is meant to provide an informal and unbiased gauge the student's perception of how the graduate attributes are being addressed in the program. Just like the mapping described in Sec. 2.4, this assessment is also multi-tiered, and must allow students to develop an understanding for what each attribute mean. Thus, in the first instances of the forum, the survey can be simplified to introduce students to these new ideas. This is accomplished by providing students with the list of 12 attributes and asked whether, in their opinion, the education they received covered addressed these areas. In the initial attempt, students are only allowed to answer $Y E S, N O$, or I don't know. Without any formal definitions, the students themselves initiate discussions on the matter and begin to map the attributes to the program using their own interpretations of the matter. Over time, as the attributes are better understood, it is possible to introduce senior students to more complex methods of assessing their experience in the program based on the attributes.

\subsection{During the Forum}

Once at the forum, students are welcomed to a room that encourages discussion and cooperation by avoiding the typical classroom setting. The student facilitators need not stand up or separate themselves from the other students, as this can quickly influence the informal grass-root atmosphere of the event. Initially, the students are invited to share both positive and negative experiences over the past term. As expected, the negative comments, complains, and small groups of vocal students can overwhelm the conversation. It is the responsibility of the facilitators to refocus the conversation, where appropriate, by prompting students about new initiatives in the department or questions posed during curriculum meetings that would benefit from a broader range of inputs. Throughout 
the forum, the facilitators are responsible for taking notes and documenting the comments to pass onto the curriculum committee for review and actions.

Some questions that have been used to engage students in conversations are [Kins10]:

- Does the program provide you with education for engineering problem solving?

- Does the program provide you with a solid theoretical foundation for analyzing, designing, implementing, and assessing new solutions to engineering problems?

- Have you achieved a balanced between education and training?

- Is there any critical subject that has been left out of the program?

- What is the greatest deficiency of the program?

- If you were to introduce one thing into the program, what would it be?

\subsection{After the Forum}

After the forum, the facilitators collect all the notes and classify them into various categories. The results from the surveys are also incorporated into the reports as they provide some quantitative feedback on the program as a whole and not just on a single course as done in SEEQ evaluations. Topics covered during the forum are summarized into main points, with feedback relevant to each point anonymized as necessary and included. Together, these results are combined into a presentation with an accompanying detailed report which was distributed to the curriculum committee. At the next curriculum meeting, the student representatives present highlights from the forum and identify the main issues as per the students' comments.

\subsection{Closing the Loop}

In order to close the feedback loop, during some forums, a professor may be invited to attend the beginning of the meeting and to summarize actions designed to address the main concerns from the previous session. The benefit of this is that students have already made a comment anonymously at the previous forum, so the professor does not direct the ideas to a single student, but rather the group present. Thus, helping younger and shier students to voice their opinions.

There is an inherited risk with soliciting input from students if the department is not going to take actions to address the concerns. If that happens, the lack of trust can hinder the relationship between professors and students and reduces the impact of future attempts to exchange information to improve the quality of an engineering program. It is obvious that there are many requests or comments from students that cannot be modified for a variety of reasons. However, that does not mean that these issues cannot be addressed with the students. Part of the process of closing the loop requires professors explain their point of view, and reasons for addressing or not addressing specific issues raised by students at that time. The sole fact that a professor took the time to communicate the reasoning behind the decisions to the students nurtures the relationship between the two parties and encourages an open dialogue of communications that is essential for a successful university program.

\section{EXAMPLE: ECE FORUMS AT THE UNIVERSITY OF MANITOBA}

The Department of Electrical and Computer Engineering at the University of Manitoba incorporated student-run forums in the curriculum development in 2010. Since then, two events are scheduled each year to encourage communications and gauge the status of the program as perceived by the students.

The first forum on February 25, 2010 attracted 18 students in $3 \mathrm{rd}, 4 \mathrm{th}$, and 5 th year of the program. The students raised a large number of issues and uncovered key areas that needed to be addressed in the program. For example, students indicated that Fourier Transform and Spectral Analysis were officially covered in the latter part of their program to be able to use the appropriate mathematical notation and analysis associated with these units. However, the students indicated that many courses in 2 nd year would benefit from at least a basic conceptual understanding of the frequency domain in order to better understand the reasoning behind some of the design decisions made by professors during class examples. When reviewing the program from an academic perspective, this kind of feedback would not appear as it requires first hand knowledge of the experience and a beginners' perspective to realize that the design assumptions must be based on fundamental concepts that form part of the core for that discipline. Other elements identified were the order of courses, suggestions for early year electives to broaden the scope of options in the final year, disconnects between laboratory work and lectures, and lots of feedback on course delivery.

In addition, the students in this forum were provided with the very simple survey of the CEAB attributes. The results are highlighted in Table 1. Some of the concerns that can be identified from these reports are the no's for communications, professionalism, impact of engineering, ethics, and economics/management and there are ongoing efforts from the department to address these issues and even clarify terms such as ethics and equity for students.

A followup meeting was scheduled on March 7, 2010 where the Associate Head of Computer Engineering attended a meeting to address and explain the actions being taken to address the students concerns and the reasoning behind some of 
Table 1: Results for CEAB portion of survey for the February 25, 2010 Computer Engineering Student-Forum

\begin{tabular}{|c|c|c|c|c|}
\hline & Question & Yes & No & Don't know \\
\hline 1 & $\begin{array}{l}\text { A knowledge base } \\
\text { for engineering }\end{array}$ & 17 & $\overline{0}$ & $\overline{1}$ \\
\hline 2 & Problem analysis & 17 & 0 & 1 \\
\hline 3 & $\begin{array}{l}\text { Critical thinking and } \\
\text { investigation of } \\
\text { problems }\end{array}$ & 17 & 1 & 0 \\
\hline 4 & $\begin{array}{l}\text { Engineering desingn } \\
\text { as an innovation } \\
\text { process }\end{array}$ & 13 & 3 & 2 \\
\hline 5 & $\begin{array}{l}\text { Use of engineering } \\
\text { tools }\end{array}$ & 14 & 1 & 3 \\
\hline 6 & $\begin{array}{l}\text { Individual and team } \\
\text { work }\end{array}$ & 18 & 0 & 0 \\
\hline 7 & $\begin{array}{l}\text { Communication } \\
\text { skills }\end{array}$ & 9.5 & 6.5 & 2 \\
\hline 8 & Professionalism & 9 & 7 & 2 \\
\hline 9 & $\begin{array}{l}\text { Impact of } \\
\text { engineering on } \\
\text { society and the } \\
\text { environment }\end{array}$ & 9 & 5 & 4 \\
\hline 10 & Ethics and equity & 8 & 5 & 5 \\
\hline 11 & $\begin{array}{l}\text { Economics and } \\
\text { project management }\end{array}$ & 10 & 6 & 2 \\
\hline 12 & $\begin{array}{l}\text { An approach for } \\
\text { life-long learning }\end{array}$ & 13 & 3 & 2 \\
\hline
\end{tabular}

the existing policies that students felt could be improved. The conversation between students and faculty during this meeting helped both parties understand the long term objectives for the program at large.

Two more forums were conducted in 2011 as part of the ongoing efforts to improve the curriculum and strenghthen the tie between faculty and students. It is worth noting that at the most recent forum, on February 10, 2011, in addition to new issues being raised, students noticed significant improvements in the laboratories for one course and made a point of sharing their enthusiasm for how the professor adapted the material for the group.

\section{CONCLUDING REMARKS}

The student-run forums are an excellent resource that complements many of the ongoing efforts to improve the curriculum for an engineering program. They provide a broad perspective on the program from different student perspectives, and can help identify key issues on content, delivery, and graduate attributes that are otherwise missed by conventional methods. The student forums provide critical feedback that can be used to improve the program by including the stu- dents (the main stakeholders) in the program shaping process, the educational experience of all parties can be improved because the students become empowered to change what requires changing, and feel ownership in the educational process.

\section{Acknowledgments}

This work was supported in part by the Department of Electrical and Computer Engineering and the Faculty of Engineering at the University of Manitoba.

\section{References}

[CEAB08] Canadian Engineering Accreditation Board, Accreditation Criteria nad Procedures, Engineers Canada, 2008.

[CEAB09] Canadian Engineering Accreditation Board, Manual of Accreditation Procedures, Engineers Canada, 2009.

[CEAB10] Canadian Engineering Accreditation Board, Accreditation Criteria nad Procedures, Engineers Canada, 2010.

[FeKi11] K. Ferens and W. Kinsner, "Industry Focus Group Forum Approach for Assessing Undergraduate Engineering Program Outcomes," in Proc. of the Canadian Engineering Education Association (CEEA/ACEG) Conference, St. John's, NL, Canada, June 6-8, 2011.

[Kins10] W. Kinsner, "Some educational issues for a student-run curriculum forum," Winnipeg, MB. Department of Electrical and Computer Engineering, University of Manitoba, February 5, 2010.

[Reme10] V. H. Remeda, "What should graduating geological engineers know and be able to do? Redesigning curricula on the basis of graduate attributes," in Proc. of the Canadian Engineering Education Association (CEEA/ACEG) Conference, Kingston, ON, Canada. June 7-9, 2011.

[Stiv10] W. Stiver, A. Bradford, S. Chang, K. Farahbaksh, D. Lubitz, J. Ryks, B. van Heyst, H. Zhou, and R. Zytner, "Engineering graduate attributes - Investigation," in Proc. of the Canadian Engineering Education Association (CEEA/ACEG) Conference, Kingston, ON, Canada. June 7-9, 2011. 